\title{
Lobbying, Counterlobbying, and the Structure of Tariff Protection in Poor and Rich Countries
}

\author{
Olivier Cadot, Jaime de Melo, and Marcelo Olarreaga
}

\begin{abstract}
A political economy model of protection is used to determine endogenously the intersectoral patterns of protection. Three propositions are derived that are consistent with the stylized patterns of tariff protection in rich and poor countries: Nominal protection rates escalate with the degree of processing, protection is higher on average in poor countries, and rich countries protect agriculture relatively more than they protect manufacturing, whereas poor countries do the reverse. Numerical simulations for archetypal rich and poor economies confirm that the endogenously determined structure of protection is broadly consistent with observed patterns of protection.
\end{abstract}

Tariff protection in rich and poor countries displays several stylized patterns. Three stand out as particularly robust. First, nominal rates of protection escalate with the degree of processing, which contributes to the widely observed escalation of effective rates of protection with the degree of processing. Second, protection is higher on average in poor countries. Third, rich countries protect agriculture more than they do manufactures, whereas poor countries do the reverse.

Until recently, analysts explained these patterns of protection largely by calling on the theory of second best. They pointed out, for example, that in rich countries farming provides a groomed landscape that benefits the whole population. ${ }^{1}$ In poor countries high trade taxes (including taxation of agriculture) are justified by the revenue constraint that because of weak fiscal administration cannot be met by less distortionary instruments. In turn, protection of manufacturing has been justified on infant-industry grounds. In each case, second-best considerations provided efficiency-based arguments justifying protection.

Olivier Cadot is professor of Economics at École de Hautes Études Commerciales, Univerite de Lausanne; his e-mail address is olivier.cadot@hec.unil.ch. Jaime de Melo is professor of Economics, Department of Political Economy, University of Geneva; his e-mail address is demelo@ecopo.unige.ch. Marcelo Olarreaga is senior economist in the Development Economics Research Group at the World Bank; his e-mail address is molarreaga@worldbank.org. This article is part of a research project on the political economy of trade protection supported by the World Bank's Research Support Budget. The authors thank Francis Ng for the data in table 1; Sanoussi Bilal, François Bourguigonn, Maurice Schiff, Alan Winters, participants at seminars at the University of Geneva and the World Bank; and three referees for comments on an earlier draft.

1. Noneconomic objectives, such as a certain degree of self-sufficiency or an income distribution objective are also often invoked as explanations for the observed pattern of protection. See Corden (1974) for an early treatment.

THE WORLD BANK ECONOMIC REVIEW, VOL. 18, NO. 3,

(C) The International Bank for Reconstruction and Development / THE WORLD BANK 2004; all rights reserved. doi:10.1093/wber/lhh042

$18: 345-366$ 
While recognizing the validity of these considerations, this article argues that an equally if not more important reason for the observed pattern of protection is rooted in the political economy considerations identified in the new political economy literature. ${ }^{2}$ This body of literature views governments not as passive executors of a trade policy to maximize social welfare but as agents interacting with organized interest groups to maximize an objective function in which social welfare is just one argument. This article shows that such an approach can generate endogenously-and perhaps more readily so than the traditional second-best literature-a predicted cross-sectoral pattern of protection that broadly fits the three stylized patterns.

\section{Literature BACKGROUnd}

Empirically, Anderson (1995) was the first to quantitatively investigate the tariffprotection pattern of agriculture relative to industry in rich and poor countries. Using a Ricardo-Viner model similar to the one developed here, data for archetypal rich and poor economies, and parameter values similar to those used here in, he shows that support to farmers in rich countries raises their incomes substantially while reducing manufacturing incomes only marginally. Conversely, agricultural taxation in poor countries reduces farmers' incomes marginally while benefiting capitalists and workers substantially. These simulations, he concludes, explain the observed pattern of protection of agriculture relative to manufacturing in rich and poor countries. Although highly suggestive, the simulations fall short of endogenizing the level and sectorial pattern of protection.

More recently, in a model nesting the economic (terms of trade) and political (redistribution toward powerful favored groups) arguments, Freund and Djankov (2000) find support for the political economy argument of protection. In a cross-section they find that proxies for political power (past share of income in the hands of the 20 percent richest groups and an index for corruption) and for favoritism (the share of public expenditures on nonpublic goods defined as expenditures other than health, education, and the social safety net) are positively related to the degree of protection. The results are robust to omitted-variable bias (distance and endowments) and to reverse causation (openness to trade, by enhancing competition, could reduce rent-seeking activity and have a negative effect on corruption; see Ades and Di Tella 1999).

Freund and Djankov's finding that favoritism has been an obstacle to trade liberalization is supportive of the approach taken here, and their finding that protection is not correlated with relative country size (the proxy for market

2. Recent empirical work (see Djankov and others 2002) also suggests that distortionary taxation of market entry tends to be associated with indicators of poor governance, themselves largely associated with low income levels. This evidence points toward explanations for observed patterns of taxation that are broadly consistent with the new political economy literature. We are grateful to a referee for attracting our attention to this point. 
power) is not surprising because tariff-setting policy is usually not associated with a country's desire to improve its terms of trade. Their approach is also consistent with the common small-country modeling approach taken here and in most of the endogenous protection literature.

This article derives Anderson's results by extending the influence-driven approach to the endogenous determination of tariffs proposed by Grossman and Helpman (1994), itself an extension of the political support approach proposed by Hillman (1982). The Grossman-Helpman approach has the advantage of relating the predicted structure of protection to potentially measurable technology and preference parameters. However, in its original formulation, it predicts that for organized sectors (those with active political lobbying) equilibrium tariff protection increases with domestic output and hence decreases with import penetration. As Rodrik (1995) points out, this prediction is not entirely realistic because it suggests, for instance, that agriculture rather than manufacturing should be protected in poor countries and is at odds with the bulk of existing empirical evidence. As argued later in this article, this apparently counterintuitive implication is not the result of a particular artifact of the Grossman-Helpman model but rather a direct consequence of Hotelling's lemma that is bound to appear in any model of influence activity. ${ }^{3}$ If the new political economy's descriptive power is to be taken seriously, therefore, reconciling the model's logic with the empirical evidence is essential.

Several solutions have been proposed to the puzzle, both empirically and theoretically. Empirically, Koujiannou-Goldberg and Maggi (1999) show that when organized and unorganized sectors are treated separately, the estimated relationship between equilibrium trade protection and import penetration is broadly in line with the Grossman-Helpman model's prediction (decreasing for organized sectors and increasing for unorganized ones). Gawande and Bandyopadhyay (2000) have similar results. Maggi and Rodriguez-Clare (1999) show theoretically that when public funds have a distortion cost and trade protection can take the form of either tariffs or quantitative restrictions, trade protection may increase with import protection under plausible conditions in the Grossman-Helpman model.

Although these studies have helped reconcile theory with the observed patterns of protection, the empirical results of Koujiannou-Goldberg and Maggi (1999) and Gawande and Bandyopadhyay (2000) are not without ambiguity, ${ }^{4}$ and Maggi and Rodriguez-Clare's (1999) extension comes at the price of substantial complication. They are thus unlikely to be the last word on an issue that is sufficiently important to deserve further exploration.

This article takes a different approach. It keeps the political game untouched but puts flesh on the underlying economy. It introduces factor-market rivalry

3. Hotelling's lemma states that at the profit-maximizing output level the derivative of profits with respect to prices is equal to output.

4. For instance, Koujiannou-Goldberg and Maggi (1999) find stronger results for unorganized sectors than for organized ones, which is problematic for a model that focuses on the effects of lobbying. 
and input-output linkages, giving rise to counterlobbying (by organized sectors other than the direct beneficiary of trade protection) and altering the equilibrium pattern of protection in a way that can reduce the gap between prediction and evidence. Indeed, it turns out that this extended model, when applied to archetypal data, yields an endogenous structure of protection that is consistent with the three stylized patterns: Nominal protection escalates with the degree of processing (because of weaker counterlobbying for processed goods), protection is higher on average for poor countries (because of sparse interindustry linkages), and rich countries protect agriculture more than they do manufactures, whereas poor countries do the reverse (because of differences in interindustry linkages and rivalry in factor markets).

In sum, this article extends the Grossman-Helpman model and the simulations by Anderson, providing a simple political economy-based account of observed protection patterns. In doing so, it provides a basis for examining the forces behind trade protection in developing and industrial countries, which is a necessary first step to any successful (and therefore lasting) trade reform.

\section{Patterns of Tariff Protection in Developed and Developing Economies}

This section provides prima facie evidence for the three stylized facts. Average tariffs by degree of processing for agricultural and industrial products for 37 developing economies and 7 industrial countries (the European Union is counted as one country), the largest available sample, provide evidence for the first two stylized facts (table 1). ${ }^{5}$ For agricultural products the average rate of

TAвLE 1. Tariff Escalation in Developing and Industrial Countries, 1997-99 (Unweighted Averages in \%)

\begin{tabular}{lcc}
\hline Stage of production & Developing & Industrial \\
\hline Agricultural products & & \\
First stage processing & 19.0 & 5.2 \\
Semiprocessed & 26.3 & 5.4 \\
Fully processed & 29.6 & 5.8 \\
Ratio of countries without escalation to sample size & $4 / 37$ & $1 / 7$ \\
Industrial products & & \\
First stage processing & 9.5 & 0.5 \\
Semiprocessed & 13.1 & 4.0 \\
Fully processed & 15.2 & 4.6 \\
Ratio of countries without escalation to sample size & $1 / 37$ & $0 / 7$ \\
\hline
\end{tabular}

Source: WTO 2000 Integrated Data Base CD-ROM and WTO Trade Policy Reviews, various issues.

5. The data are from the World Trade Organization (WTO) Integrated Data Base version 4 and the wToTrade Policy Reviews. 
protection rises by degree of processing for both the developing country group and the industrial country group. Fully processed agricultural goods have a 55 percent higher tariff on average than goods in their first stage of processing in developing areas and a 12 percent higher tariff in industrial countries. ${ }^{6}$ Protection also rises on average with the degree of processing for industrial products. However, fully processed industrial products receive about 55 percent more protection than first-stage processing products in developing economies and 450 percent more in industrial countries.

Because classifying products by degree of processing is subject to error, a more robust estimate of the effect that processing has on tariff structure might compare first-stage and fully processed products. For agriculture products only five countries do not conform to the prediction that tariffs are higher for fully processed goods: China, Republic of Korea, South Africa, Thailand, and Norway). For industrial products, only, Romania does not conform. By this classification the predicted pattern holds in 93 percent of the cases. ${ }^{7}$

On the second stylized fact, that protection is higher in developing economies, a quick look at table 1 suggests that this is the case for both agriculture and industry across all levels of processing.

The third stylized fact is that industrial countries tend to protect agriculture more than manufacturing, whereas the opposite is true for developing areas. The ploting of a curve linking the average relationship (by decile) between protection of manufacturing relative to agriculture and gross domestic product (GDP) per capita of a sample of 81 countries shows a negative relation (figure 1). ${ }^{8}$ The relative protection variable is $t_{M} / t_{A}$, where $t_{M}$ and $t_{A}$ are unweighted average tariffs for manufactures and agriculture for a sample of 81 countries (the largest available sample with data on tariffs and GDP per capita, $Y_{P}$ ). The gain in number of countries covered by using only tariffs rather than all forms of protection, comes at a cost, however. Because these estimates do not include the effects of other price measures (such as export taxes) and nonprice measures (such as nontariff barriers), figure 1 cannot be said to be representative of

6. Note however, that all developed countries use specific tariffs intensively in agriculture and that the WTO's Integrated Data Base does not provide ad valorem equivalents of these tariffs. Including specific tariffs could show a more dramatic picture.

7. One could also object that the pattern of protection in manufactures is the result of bargaining through successive rounds of tariff negotiations rather than determined noncooperatively at the national level, as predicted by the political economy approach developed here. However, because the current observed pattern is largely the result of successive linear across-the-board reductions, it is likely that the current pattern reflects, as a first approximation, patterns established before the multilateral tariff cuts. Ray (1990) discusses how these patterns were established along political economy grounds similar to those explored in this article.

8. The data on agriculture and manufacturing tariffs are compiled from various sources, including WTO, UNCTAD, and the World Bank and are available online at www.worldbank.org/research/trade. The GDP per capita data are from World Bank (2000). Note that the sample is larger than that in table 1 because the disaggregated tariff data necessary to compute average tariffs by levels of processing are not available for some countries. 
Figure 1. Relative Protection of Manufacturing and Income per Capita, 1995-2000

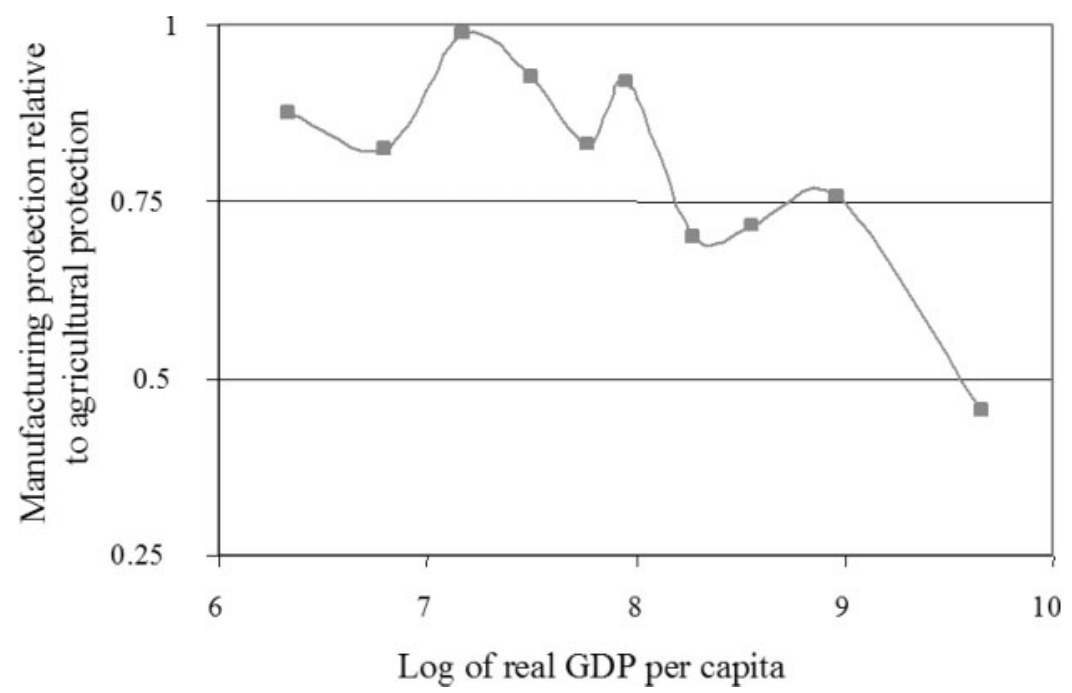

Source: WTO 2000 CD-ROM International Trade Statistics and WTO Trade Policy Reviews, various issues for tariff data; World Bank 2000 for GDP per capita.

the relative incentives to agriculture and manufactures as income per capita varies.

The negative relation between protection of manufacturing relative to agriculture and the log of income per capita is confirmed by the results of the following regression, for which $F(1,79)=9.27$, with the $t$-statistic in parentheses.

$$
t_{M} / t_{A}=\underset{(5.77)}{1.68}-\underset{(3.04)}{0.11} Y_{P}
$$

The relation, which is significant despite a few outlier observations (including Australia and Turkey), indicates that the relative tariff of agriculture over manufactures increases by 1.1 percent for each 10 percent increase in GDP per capita.

It is likely that the positive relation between the relative protection of agriculture and the level of GDP per capita would have been even more striking had data been available on producer subsidy equivalents for all countries and had more indicative data been available on protection for agriculture in developing countries, along the lines of the Krueger and others (1989) estimates.

\section{Determinants of the Structure of Protection}

The model presented next is an extension of the basic Grossman-Helpman model, with which it shares several elements. First, the political game is the same. Namely, lobbies "bid for protection" through monetary contributions conditioned 
on the level of tariffs, and the government maximizes a weighted average of social welfare and contributions. Alternatively, the government can be seen as acting as the common agent of the lobbies. The government's objective function is a linear (but not necessarily convex) combination of welfare and monetary contributions from the lobbies.

Second, the underlying economy is similar in most regards. The lobbies represent the interests of specific-capital owners in a Ricardo-Viner model, and individuals have identical quasilinear preferences. The differentiating elements introduced here are that specific-capital ownership is assumed to be sufficiently concentrated that lobbies care only about protecting their industry (they do not internalize the effect of protection on consumer prices), all sectors are assumed to be politically organized (actively lobbying), and all sectors combine specific capital with mobile labor. This symmetry in factor use across sectors relaxes a key assumption in the Grossman-Helpman model-that the existence of a sector operating with labor only under constant returns to scale fixes the wage rate. The interest of relaxing this assumption is that a flexible wage rate introduces intersectoral rivalry in the labor market, with one sector's protection raising the cost of labor for other sectors.

Finally, all goods may enter as input into the production of all other goods, so that one sector's protection raises the costs of other sectors. This creates a second channel of intersectoral rivalry, through input-output linkages.

These new elements create the possibility of counterlobbying: In this model one sector's lobbying for protection meets political opposition from other sectors. The equilibrium pattern of protection results from the net effect of these opposing forces. These extensions generate a pattern of protection that no longer needs to share the unfortunate features of the basic Grossman-Helpman model.

\section{Lobbying in a Specific-Factor Model}

Consider a small open economy with $n+1$ tradable sectors, in which good 0 serves as numéraire and export good. All $n$ other goods are import competing. Individuals have different endowments but identical tastes, represented by a utility function:

$$
U=c_{0}+u(\mathbf{c})
$$

where $c_{0}$ is consumption of the numéraire good, and $\mathrm{c}$ is the vector of consumption of the $n$ non-numéraire goods, $u^{\prime}>0$ and $u^{\prime \prime}<0$.

All goods produced in the economy are potential inputs in other sectors, and all industries are perfectly competitive. Each sector's technology is Leontief between intermediate consumptions and value added. Thus, value added is nested in the Leontief production function and is created using a specific factor $\left(\kappa_{j}\right)$ and a mobile factor $\left(\ell_{j}\right)$ under a general constant returns to scale technology $\left(f^{j}\right)$. Letting $a_{i j}$ be the requirement of good $i$ necessary to produce one unit of good $j$, and letting $x_{i j}$ be sector $j$ 's demand for good $i$ as an intermediate input, 


$$
y_{j}=\min \left\{f^{j}\left(\kappa_{j}, \ell_{j}\right) ; x_{0 j} / a_{0 j} ; \ldots ; x_{n j} / a_{n j}\right\}
$$

The world prices of all goods are fixed and assumed to be unity. The domestic price of good $i$ is thus $p_{i}=1+t_{i}$, where $t_{i}$ is the specific tariff (or subsidy if it is negative) applied to it. Let $\mathbf{p}=\left(p_{1}, \ldots, p_{n}\right)$ be the vector of domestic prices and $w$ the wage rate, and let $\tilde{p}_{j}=p_{j}-\Sigma_{i=0}^{n} a_{i j} p_{i}$ be the net price of good $j$. Given the technology postulated, industry $j$ 's restricted profit function can be written as $\pi_{j}\left[\kappa_{j} ; \mathbf{p} ; w(\mathbf{p})\right]=\tilde{p}_{j} y_{j}-w \ell_{j}$. Lobbies representing import-competing sectors (all are assumed to be organized) bid simultaneously for protection with "truthful" contribution schedules $C_{j}(\mathbf{p})=\max \left\{0 ; \pi_{j}-b_{j}\right\}$ for some nonnegative constant $b_{j}{ }^{9}$ The form of the contributions reflects the assumption that lobbies are very small in the population. Thus, from their point of view, the effects of protection on consumer surplus and tariff revenue are not commensurate with the direct effect of protection on producer surplus, and they take only that direct effect into account in their lobbying activity.

Faced with such contributions, the government chooses best-response tariffs (domestic prices) maximizing

$$
V(\mathbf{p})=\sum_{j=1}^{n} C_{j}(\mathbf{p})+a W(\mathbf{p})
$$

where $W(\mathbf{p})$ is social welfare and $a$ is a constant representing the weight the government attaches to social welfare. ${ }^{10}$ Domestic prices satisfy the first-order condition:

$$
\partial V(\mathbf{p}) / \partial p_{i}=\sum_{j=1}^{n}\left(\partial \pi_{j} / \partial p_{i}\right)+a\left(\partial W / \partial p_{i}\right)=p_{i}+a \varepsilon_{i}=0
$$

which picks up the net effect of protection in sector $i$ on economywide rents and measures the incentive for the government to depart from the optimal secondbest tariff in sector $i$. The first term in the equation is the "net political-power component," because it measures the ability of lobby $i$ to make its voice heard above that of opposing lobbies; this term is denoted by $\Phi_{i}$. Using Hotelling's lemma, $\partial \pi_{j} / \partial p_{i}=\left(1_{j=i}-a_{i j}\right) y_{j}-\ell_{j} \partial w / \partial p_{i}$, where $1_{j=i}$ is an indicator function equal to one when $j=i$ and zero otherwise. Thus, under the assumption that all sectors are politically organized, the effect of a change in $p_{i}$ on aggregate political contributions (on producer surplus in all sectors) is:

9. The vector of constants $b_{j}$ determines how the rents from trade protection are shared between the government and lobbies; see Grossman and Helpman (1994).

10. Grossman and Helpman (1996) show that this objective function emerges in a political system in which lobbies use campaign contributions to influence the outcome of the election, while two parties compete for seats in Parliament. However, whether such an objective function is representative of the objective function in low-income countries is more debatable. For a skeptic's view, see Findlay (1991). 


$$
\Phi_{i} \equiv \sum_{j}\left(\partial \pi_{j} / \partial p_{i}\right)=y_{i}-\sum_{j} a_{i j} y_{j}-\ell\left(\partial w / \partial p_{i}\right)
$$

where $\ell=\sum_{j} \ell_{j}$ is the economy's total labor force.

The first term in $\Phi_{i}$ reflects the direct effect of trade protection on the profits of sector $i$-the rent accruing to owners of sector-specific capital in sector $i$. This term is at the origin of the import-penetration controversy. To see this, observe that the larger an industry's domestic output, the larger is (through Hotelling's lemma) the impact of a given tariff increase on its profits. Through the truthfulness assumption, this implies a higher lobbying intensity, which raises the power of the incentive given to the government. Accordingly, in equilibrium the government grants larger protection. But for a given level of demand a larger domestic output reduces the import-penetration ratio, hence the negative association between import-penetration ratios and equilibrium protection. As mentioned, this result is not a modeling artifact but goes to the heart of the influence-activity logic: Whenever lobbying is done by an industry's residual claimants, through Hotelling's lemma a larger domestic output will raise the return to lobbying.

In the Grossman-Helpman model, the story stops here. The only way out of this unfortunate prediction is to note, as Koujiannou-Goldberg and Maggi (1999) do, that the positive relationship between output size and equilibrium protection holds only for organized industries. For unorganized ones the relationship is reversed, at least provided that special interests take consumer effects into account.

Though not contesting this observation, the model here focuses on another effect that also solves the puzzle but generates distinct predictions as by-products. All sectors are assumed to be organized, an assumption that is easily relaxed but at the cost of additional notation. The novelty here comes in the next two terms in equation 6, which reflect the two components of rivalry between lobbies; the stronger the rival lobbies, the lower the level of rent extraction by lobby $i$. The first term $\left(\sum_{j} a_{i j} y_{j}\right)$ represents the impact of protection in $i$ on downstream sectors through input-output linkages. An increase in the tariff on good $i$ reduces the net price $\tilde{p}_{j}$ of all downstream sectors (all sectors $j$ such that $a_{i j}>0$ ), giving rise to counterlobbying. The last term in equation 6 represents crowding out through the wage rate: As the tariff on good $i$ rises, sector $i$ expands, bidding up the wage rate, penalizing other sectors, and giving rise to counterlobbying. In general, the political power component, $\phi_{i}$, need not be positive, as general-equilibrium spillovers through input-output and labor-market linkages may more than offset any gains from protection accruing to sector $i$.

The second term $\left(\partial W / \partial p_{i}\right)$ in equation 5 picks up the effect of protection on social welfare and summarizes second-best considerations. It is labeled the "efficiency component" and is denoted by $\varepsilon_{i}$. (The derivations of $\varphi_{i}, \mathscr{E}_{i}$ are given in appendix 1.)

Although protection in one sector generates negative downstream spillovers through input-output linkages, it does not generate positive spillovers in 
upstream (tradable) sectors, because tradables prices (equal to $1+t_{i}$ for all $i$ ) are unaffected by variations in domestic demand. By contrast, if there were an upstream nontradables sector-a situation not considered formally here or in the simulations for space considerations-its profits would be boosted by protection downstream, because the nontradable's price would be sensitive to variations in domestic demand. Ad hoc coalitions of interests could then form between tradables and nontradables sectors.

\section{Explaining the Three Stylized Facts}

Proposition 1 shows that when interindustry linkages are taken into account, the net political power of an industry increases with the amount of that industry's sales to final consumers rather than with its overall output. The first two corollaries help explain the first two stylized facts (tariff escalation and higher levels of protection in poor countries). Proposition 2 shows that sectors that employ a large share of the labor force face stronger counter-lobbying due to factor market rivalry. Corollary 3 helps explain the third stylized fact (higher levels of agricultural than manufacturing protection in rich countries and the reverse in poor countries).

Proposition 1. The net political power of sector i increases with the level of sector i's sales to final users. Moreover, when its free-trade level of output falls short of other sectors' intermediate requirements of good i by a sufficiently large amount, sector i may get negative protection in equilibrium.

Proof. The first statement follows directly from the observation that $P_{i}$ is an increasing function of $y_{i}-\sum_{j} a_{i j} y_{j}$, which is that part of final domestic consumption covered by domestic output. For the second statement, fix all prices except $p_{i}$ at their equilibrium level and $p_{i}$ at its free-trade level $\left(p_{i}=1\right)$. If $y_{i}<\sum_{j} a_{i j} y_{j}, p_{i}<0$, provided that the second-best term $\mathscr{E}_{i}$ is nonpositive or, if positive, not sufficiently large as to offset the political power term $\varphi_{i}, \partial V / \partial p_{i}=p_{i}+a_{\varepsilon_{i}}<0$. Under the second-order condition, $\partial V / \partial p_{i}$ is a decreasing function of $p_{i}$; therefore, the equilibrium value of $p_{i}$ must be lower than 1 , which implies negative protection for good $i$.

Thus, it is the fraction of sector $i$ 's output that is sold to final consumers (or exported in the case of an export industry bidding for subsidies) that determines how much protection sector $i$ gets in equilibrium. This is because unlike domestic downstream industries, neither final consumers nor foreign users are organized. Proposition 1 yields a second result as a by-product.

Corollary 1. The net political power of final-goods industries is greater, ceteris paribus, than that of intermediate-goods industries.

In a political equilibrium final-goods industries, which in most cases correspond to the fully processed goods industries mentioned earlier, are likely to obtain more protection than intermediate-goods industries unless output levels vary systematically and inversely with the degree of processing and this systematic variation is large enough to undo the negative effect of the term $\sum_{j} a_{i j} y_{j}$. Barring 
this, the overall structure of protection will display tariff escalation. ${ }^{11}$ This result accords with the data in table 1 (see also Ray 1990) and helps explain the first stylized fact. It is also in accordance with the more detailed accounts in industry case studies of protection. For example, Moore (1996) notes in his study of protection in the U.S. steel industry that organized steel users joined forces to prevent an extension of the 1984 voluntary restraint agreement on steel imports. Destler and Odell (1987) offer similar arguments on the importance of counterlobbying.

If one is willing to accept that more developed economies have more sophisticated and interlinked production techniques (a lower share of value added to output), then the second stylized fact is also a corollary of proposition 1:

Corollary 2. Tariffs are higher, ceteris paribus, in countries with sparse interindustry linkages (developing countries).

To see this, note that $\partial P_{i} / \partial a_{i j}<0$. Thus poor countries tend to have higher levels of protection, because there are few incentives for other sectors to counterlobby increases in protection on intermediate inputs when interindustry linkages are sparse.

Proposition 2. Incentives for owners of sector-specific capital in sector i to lobby for protection decrease with that sector's share of labor in value added.

Proof. Abstract from interindustry linkages so that $\Phi_{i}$ in equation A6 in appendix 1 becomes $\Phi_{i}=y_{i}\left[1-\tilde{\varepsilon}_{i}^{w} \tilde{\alpha}_{i} / \lambda_{i}\right]$, where $\tilde{\varepsilon}_{i}^{w}$ is the elasticity of the wage with respect to the price of good $i, \lambda_{i}$ is the share of employment in sector $i$ in the total labor force $\left(\lambda_{i}=\ell_{i} / \ell\right)$, and $\tilde{\alpha}_{i}=w \ell_{i} / \tilde{p}_{i} y_{i}$ is the share of labor in value added. Given that labor is in fixed supply, $\tilde{\varepsilon}_{i}^{w}=\left(\eta_{i} \ell_{i} / \sum_{j} \eta_{j} \ell_{j}\right)$ where $\eta_{i}$ is the real wage elasticity of labor demand in sector $i$. Furthermore, assuming that $\eta_{i}$ is identical across sectors, $\tilde{\varepsilon}_{i}^{w}=\lambda_{i}$. Then, $\Phi_{i}=y_{i}\left[1-\tilde{\alpha}_{i}\right]$. Finally, $\partial P_{i} / \partial \tilde{\alpha}_{i}<0$.

Thus the labor rivalry term is increasing in the share of labor in sector $i$ 's value added. In a setting with flexible wages incentives to lobby for protection by owners of sector-specific capital are likely to be small in industries where a large share of value added can be attributed to labor.

Finally, if one is willing to accept that the share of labor in value added in agriculture relative to manufacturing is higher in developing economies-as suggested by the calibration of Anderson (1995) and Chenery and Syrquin's (1986) data in the simulations below (table B-2) - then the explanation for the third stylized fact is that:

Corollary 3. The ratio of agricultural to manufacturing tariffs will be lower, ceteris paribus, in countries where the share of labor in value added is higher in agriculture than in manufacturing (low-income developing countries).

11. Note that the Leontief technology implies that downstream users of a protected intermediate good are trapped, as they cannot escape the intermediate good's increased domestic price by substituting away from it. With a different technology, input substitution would be an alternative to lobbying against the intermediate good's protection; with a lesser incentive to counterlobby, the tariff-escalation result would be weakened. 
According to the data calibration in the next section, in developing areas the share of labor in value added is two times greater in agriculture than in manufacturing. In industrial countries, by contrast, the share of labor in value added is 30 percent larger in manufacturing than in agriculture. According to corollary 3 , this could help explain the third stylized fact.

\section{Simulations: Endogenous Protection in Archetypal Rich and Poor Economies}

The propositions are ceteris paribus results pertaining only to the political power term in the endogenous-tariff formula, with second-best terms held constant. Relaxing this assumption in simulations can help show how consistent the model's predictions are with the stylized facts presented earlier. Partial equilibrium simulations are conducted for archetypal rich and poor economies with data for three-sector economies with two tradables sectors, agriculture and industry, and one nontradeables sector. ${ }^{12}$ The simulations are based on a disaggregation of the economy that includes interindustry flows, a key element of lobby rivalry highlighted by the model. Data sources and parameters representing demand and supply elasticities are described in appendix B and come mainly from Anderson (1995) and Chenery and Syrquin (1986).

On the basis of the data on the two archetypal economies, Anderson calculated the effects on the income of farmers and industrialists of a 10 percent rise in the relative price of industrial products as a result of a tax on agricultural exports. This relative price change reduced farmers' incomes by less than 4 percent while boosting industrialists' real incomes by 40 percent. Results were similar for an increase in the relative price of industrial products that had a small negative effect on farm incomes. By contrast, for the rich economy, a 10 percent increase in agricultural relative prices would boost real farm incomes by 23 percent while lowering industrial incomes by only 3 percent. His simulations suggest that farmers in poor countries who successfully seek price supports or oppose industrial protection would get only one-sixth to one-ninth the benefits of farmers in rich countries who successfully engage in the same activities. Likewise, industrial capitalists in poor countries would have more than 10 times the incentive to seek policies to protect manufacturing and reduce agricultural prices than would industrialists in rich countries.

Anderson conjectures that this adjustment pattern helps explain the difficulties encountered in concluding the Uruguay Round of negotiations, because farm lobbies in industrial countries opposed reductions in farm support. But this observation falls short of fully explaning the observed pattern of protection

12. The words "rich" and "poor" other are used only to indicate the differences in economic structure observed between countries, as in Chenery and Syrquin (1986), for example. This is the choice of names in Anderson (1995), kept here for continuity. 
in rich and poor economies. The simulations reported in this article show that Anderson's conjecture emerges endogenously in this model of tariff determination. Moreover, the ability of the Grossman-Helpman model to generate this particular pattern of protection comes specifically from the extensions introduced here.

The simulations are based on a numerical evaluation of equations 5 , A-6, and A-5, which are indexed over two tradables sectors (agriculture and manufacturing), though the economy also includes a third, nontradables sector (for consistency with Anderson [1995] and with the Chenery and Syrquin [1986] data). The wage appears as a variable in these equations. This requires adding an equation for determining labor demand for each sector as well as a labor-market constraint $\left(\sum_{i} \ell_{i}=\ell\right)$ determining the equilibrium wage rate.

Thus, the three-sector model used here has seven equations: two determine the tariffs, three determine cost-minimizing labor demand $\left(\ell_{i}\right)$, and one determines the market-clearing wage rate $(w)$. (Appendix B describes the equations used in these partial-equilibrium simulations.) Because the income-expenditure link is not specified in this system of equations, the model is closed by fixing the price of the nontradables sector. ${ }^{13}$ The solution to this model yields tariffs for tradables sectors, labor allocations that clear the labor market, and the value of the wage in terms of the price of the nontradables sector.

This model is best viewed as an approximate local calculation of an equilibrium tariff structure for the selected elasticities of demand and supply (described in table A-2) and an exogenously given preference (given by the parameter $a$ ) for the welfare of the representative consumer. ${ }^{14}$ For low enough values of the weight attached to welfare $(a)$, the first-order condition of the optimization problem might yield a minimum of the function $V$, rather than a maximum. In other words, tariffs may be high enough to give rise to negative value-added prices. Such cases are not considered here.

For variations in the weight attached to welfare $(a)$, the model predicts the endogenous tariff rates for the two archetypal economies (table 2). As expected, for both economies the greater the weight politicians attach to welfare, the lower the rate of protection. For sufficiently large weights, tariffs tend to zero. Next, note that the average level of protection is lower in the rich economy. The ratio of value added to output is lower for the rich economy ( 55 percent) than

13. Eliminating the tradables-nontradables link by omitting the income-expenditure link is justifiable for this illustrative exercise. Simulations here are meant to check only whether the model can reasonably support the stylized facts. Conditions under which this partial equilibrium approach is valid in a general equilibrium model identical to this one are given in Dornbusch (1974).

14. Evaluation of the formula in the text is based on elasticities that are valid only for small changes around the equilibrium. Moreover, some of those elasticities are endogenously determined; for instance, price elasticities of the wage rate depend, at a cost-minimizing equilibrium, on the elasticity of substitution and on the elasticity of labor demand, whose calculation depends on domestic prices, which in turn include a guess about the tariff value. Systematic experimentation with several starting values always yielded the same solution. 
Table 2. Endogenous Tariff Structure in Rich and Poor Countries (\%)

\begin{tabular}{|c|c|c|c|c|c|c|}
\hline & \multicolumn{3}{|c|}{ Rich } & \multicolumn{3}{|c|}{ Poor } \\
\hline & $a=1.5^{\mathrm{a}}$ & $a=2$ & $a=10$ & $a=1.5^{\mathrm{b}}$ & $a=2$ & $a=10$ \\
\hline Average agricultural tariff & 52.5 & 27.7 & 3.3 & 30.1 & 23.3 & 5.9 \\
\hline Average manufacturing tariff & 16.8 & 11.5 & 1.9 & 69.7 & 47.7 & 9.2 \\
\hline Aggregate tariff & 20.9 & 13.3 & 2.0 & 35.6 & 26.7 & 6.4 \\
\hline
\end{tabular}

Note: $a$ is the weight politicans attach to the welfare of the representative consumer.

af $a<1.25$, the solution is not unique.

bIf $a<1.25$, the optimization problem yields a minimum.

Source: See appendix B.

for the poor economy (74 percent), so that stronger counterlobbying by downstream users in the rich economy reduces the average rate of protection. But the most striking result is the pattern of protection. In accordance with the stylized facts, the pattern of incentives systematically favors manufacturing in the poor economy and agriculture in the rich economy. In the simulations reported in table 2, agriculture is a net exporting sector in the poor economy and industry is in the rich economy. Thus it is not necessarily true that the endogenous tariff and subsidy structure results in large sectors receiving higher protection because of their larger political weight.

There is no doubt that other factors-limited means of taxation in poor countries and lack of political power by all but a tiny minority of farmers to organize themselves into lobbying activities-are important in explaining the relative pattern of incentives between agriculture and industry in poor and rich economies. Nonetheless, by taking account of intermediate goods and assuming a greater variation in the pattern of elasticities across sectors in poor countries, this model generates a pattern of protection that conforms to the one observed: higher protection and greater variance of tariff rates in poor than in rich economies. But because manufacturing activities are aggregated into a single activity, it is difficult to verify whether the endogenously determined tariff structure captures the escalation in protection by degree of processing. Overall, however, these archetypal representations appear to capture adequately the main differences in the pattern of protection between rich and poor economies. They are broadly consistent with the stylized facts on the pattern of protection in rich and poor countries.

Sensitivity calculations for the rich country archetype help establish the robustness of results to underlying assumptions about parameter values (table 3). For reference, the results from applying the Grossman-Helpman formula are also reported. Not surprisingly, because the Grossman-Helpman model has no intermediate goods, their formula yields a higher level of protection.

Column 1 of table 3 reproduces the result of table 2 for $a=2$; the other columns report the results of one-by-one variations from this baseline case. Columns 2 and 3 cut the input-output delivery coefficients for manufacturing 
Table 3. Sensitivity Analysis for the Rich Economy

\begin{tabular}{llllllllll}
\hline & Base $^{\mathrm{a}}$ & $a_{M j} / 2$ & $a_{A j} / 2$ & $\varepsilon_{M}^{w}=0$ & $\varepsilon_{A}^{w}=0$ & $\varepsilon_{M M}^{c} / 2$ & $\varepsilon_{A A}^{c} / 2$ & $\sigma^{A}=0.8 \sigma^{M}=1.2$ & $\mathrm{G}^{2} \mathrm{H}^{\mathrm{b}}$ \\
\hline & $(1)$ & $(2)$ & $(3)$ & $(4)$ & $(5)$ & $(6)$ & $(7)$ & $(8)$ & $(9)$ \\
$\mathrm{T}^{A}$ & 27.7 & 39.8 & 86.2 & 24.2 & 56.3 & 22.2 & 31.6 & 38.3 & 42.4 \\
$\mathrm{~T}^{M}$ & 11.5 & 32.5 & 11.4 & 25.3 & 10.8 & 12.1 & 11.3 & 7.2 & 30.6 \\
$\bar{T}$ & 13.3 & 33.3 & 20.0 & 25.2 & 16.0 & 13.3 & 13.7 & 10.6 & 31.9 \\
\hline
\end{tabular}

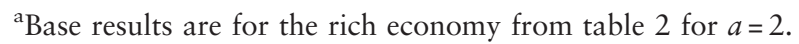

${ }^{b}$ Calculated from Grossman and Helpman (1994), Proposition 2, and note 10 under the assumption of no consumer participation in interest groups.

Source: See appendix B.

and agriculture in half. In both cases smaller intermediate sales reduce counterlobbying from other sectors, yielding higher protection for the sector. When the manufacturing sector's input-output delivery coefficients are cut, protection of agriculture also rises. This is because the reduction in the agricultural sector's requirement for manufactured goods raises its equilibrium profits (in spite of the higher price of manufactured goods), leading to stronger agricultural lobbying.

Columns 4 and 5 isolate the general equilibrium effects of the wage rate adjustment by setting the price elasticity of the wage rate to zero. This may be viewed as the most relevant closure empirically, because it could be argued that general equilibrium effects are not central to lobbyists' decisions. Although not reported, the pattern of protection in which agriculture is protected relative to manufacturing holds when both elasticities are simultaneously set to zero. This closure amounts to determining the tariff of a small sector in the sense that changes in that sector's demand for labor have no influence on the equilibrium wage rate. As explained in section II, there is less counterlobbying, and in this highly aggregated model with only three sectors this effect is quantitatively important, resulting in a near doubling of the sector's endogenous tariff. ${ }^{15}$

Columns 6-8 consider second-best effects by varying demand and supply elasticities. A reduction in the own-price elasticity of demand in one sector reduces its elasticity of import demand, in turn reducing the welfare cost of protection in that sector. ${ }^{16}$ The same effect is at work in the simulation reported in column 8: A departure from unitary elasticities of substitution in production

15. Though in a different context, this experiment is reminiscent of the thought experiment performed by Mayer (1984) in a direct democracy setting. In a Ricardo-Viner economy he showed that sectors with weaker wage complementarities (by which he meant weaker effects of one sector's tariff on the equilibrium wage rate) are more likely to get support and obtain protection.

16. Ramsey effects also explain why cutting the price elasticity of demand in manufacturing reduces the variance of tariffs, whereas cutting the same elasticity in agriculture raises their variance. In the case of the reduction in the elasticity of demand for manufacturing, the differential in the pattern of elasticities is reduced, whereas in the case of agriculture the opposite occurs. Thus a reduction in the elasticity of demand for manufacturing leads to a more uniform pattern of protection, but the opposite occurs with a reduction in the elasticity of demand for agriculture. 
also raises the differential in elasticities of supply. By second-best considerations, this results in a greater dispersion of the tariff structure.

\section{Concluding Remarks}

This article introduced two extensions to the Grossman-Helpman framework: vertical (input-output) linkages and interindustry rivalry on labor markets. These extensions, though involving minimal additional complication, are potentially useful in several ways.

First, they help overcome a basic contradiction between the logic of influenceactivity models and empirical evidence (and intuition). According to the model's logic, a higher level of domestic output raises the return to lobbying. In a common-agency context this leads lobbies to face governments with steeper incentive schedules, leading to more generous trade protection in equilibrium. Intuition and empirical evidence, however, suggest that lobbying intensity and the government's protectionist response should increase with the perceived threat of import competition (with rising import-penetration ratios). The gist of the approach here is to show that equilibrium protection is the result not just of lobbying pressures from direct beneficiaries of protection but also of counterlobbying by negatively affected downstream industries. This argument is distinct from the Grossman-Helpman notion that producer lobbies internalize consumption effects, which requires them to be large enough in the population. This extension of the Grossman-Helpman approach suggests that, empirically, the relationship between domestic output and equilibrium protection may be blurred by potentially larger effects having to do with counterlobbying.

Second, these extensions suggest a pattern of trade protection that displays tariff escalation by degree of processing, an empirical regularity that cannot be accounted for by the basic version of the Grossman-Helpman model, which superimposes a sophisticated political game on an overly stripped-down economy.

Finally, the extended Grossman-Helpman model can generate endogenously a pattern of protection suggested by Anderson (1995), whereby poor countries protect industry relative to agriculture while rich ones do the reverse. Thus the message is that the apparent difficulty of reconciling the logic of the GrossmanHelpman model with stylized facts comes not so much from the political game at the center of their analysis as from the straitjacket of an overly simplistic underlying economy. Once the straitjacket is relaxed, the model proves capable of generating a wealth of plausible implications.

The analysis is perforce essentially positive rather than normative, a characterization that applies to the entire political economy literature. Indeed, the central tenet of this literature is that irrespective of what economists think governments ought to do, economists first need to understand what governments actually do and why they do it, which requires a realistic view of the objectives and constraints of elected political representatives. Normative 
prescriptions are thus thrown back one step, into recommendations for institutional arrangements capable of mitigating policy capture by special interests.

However, useful if somewhat impressionistic policy considerations can emerge as by-products of this positive analysis. For instance, the emphasis on counterlobbying suggests that in conformity with the general logic of commonagency models, good policies do not necessarily come from politicians maximizing "welfare-friendly" objective functions or operating under tight rules, but possibly from the balance of conflicting special-interest pressures. Conversely, bad policies can result from imbalances in lobbying pressures and from institutional arrangements that weaken pressure from one side aggravate distortions. For instance, duty-drawback schemes can be expected to weaken antiprotectionist pressure from downstream users of import-competing goods, which may well lead to higher tariffs on intermediate products. This idea is pursued theoretically and shown to hold empirically in Cadot and others (2003).

\section{Appendix A. Derivation of the Efficiency and Political Effects}

At any point the economy is characterized by its income-expenditure identity, namely

$$
E(1, \mathbf{p}, W) \equiv R(1, \mathbf{p}, \mathbf{k}, \ell)+T(\mathbf{p})
$$

where 1 is the price of the numéraire, $E($.$) is the economy's expenditure func-$ tion, $\mathrm{R}($.$) is its revenue function, \mathbf{k}$ is the vector of $n+1$ specific factors, and $\mathrm{T}($. is tariff revenue. The homogeneity properties of equation A-1 implies that only relative prices can be determined. Differentiating this identity with respect to $p_{i}$ and letting $E_{i}$ stand for the partial derivatives of the expenditure and $R_{i}$ for revenue functions with respect to $p_{i}$ gives

$$
E_{i}+E_{W}\left(\partial W / \partial p_{i}\right)=R_{i}+\left(\partial T / \partial p_{i}\right) .
$$

Let $m_{i}$ stand for sector $i$ 's import-demand function, $c_{i}$ and $y_{i}$ being respectively the domestic consumption and production of $\operatorname{good} i$, and $a_{i j}$ the input-output coefficients. Rearranging equation A-2 and using Shephard's and Hotelling's lemmas, together with the fact that the marginal utility of income is 1 under equation 2 , we have

$$
\partial W / \partial p_{i}=-m_{i}+\left(\partial T / \partial p_{i}\right) .
$$

Choose units so that all international prices are equal to one, and let $t_{i}=p_{i}-1$ be the tariff rate. Tariff revenue can be written as $T(p)=\sum_{j} t_{j} m_{j}(p)$, so that

$$
\partial T / \partial p_{i}=m_{i}+\sum_{j} t_{j}\left(\partial m_{j} / \partial p_{i}\right)
$$


Substituting this into equation A3 gives

$$
\partial W / \partial p_{i}=\sum_{j} t_{j}\left(\partial m_{j} / \partial p_{i}\right)=\sum_{j} t_{j}\left(\left[\partial c_{j} / \partial p_{i}\right]+\sum_{k} a_{j k}\left[\partial y_{k} / \partial p_{i}\right]-\left[\partial y_{j} / \partial p_{i}\right]\right)
$$

which confirms that supply of good $j$ is a function of the "net price" of good $j$, $\tilde{p}_{j}=p_{j}-\sum_{j} a_{k j} p_{k}$, and of the wage rate. Thus,

$$
\partial y_{k} / \partial p_{i}=\left(\partial y_{k} / \partial \tilde{p}_{k}\right)\left(\partial \tilde{p}_{k} / \partial p_{i}\right)+\left(\partial y_{k} / \partial w\right)\left(\partial w / \partial p_{i}\right)
$$

Collecting terms,

$$
\begin{aligned}
\partial W / \partial p_{i} & =\sum_{j} t_{j}\left(c_{j} / p_{i}\right) \varepsilon_{i j}^{c} \\
& +\sum_{j} t_{j}\left[\sum_{k} a_{j k}\left[\partial y_{k} / \partial \tilde{p}_{k}\right]\left[\partial \tilde{p}_{k} / \partial p_{i}\right]-\left[\partial y_{j} / \partial \tilde{p}_{j}\right]\left[\partial \tilde{p}_{j} / \partial p_{i}\right]\right. \\
& \left.+\left(\sum_{k} a_{j k}\left[\partial y_{k} / \partial w\right]-\left[\partial y_{j} / \partial w\right]\right)-\left(\partial w / \partial p_{i}\right)\right]
\end{aligned}
$$

Let $\tilde{\varepsilon}_{i}^{s}=\partial \log y_{i} / \partial \log \tilde{p}_{i}(>0)$ be the elasticity of supply to the net price of good $i, \mu_{i}=-\partial \log y_{i} / \partial \log w(>0)$ the wage elasticity of supply in sector $i$, and $\varepsilon_{i j}^{c}=\partial \log c_{j} / \partial \log p_{i}$ the cross-price elasticity of final demand in sector $i$. Using the fact that

$$
\partial \tilde{p}_{k} / \partial p_{i}= \begin{cases}1-a_{i i} & \text { for } k=i \\ -a_{i k} & \text { otherwise }\end{cases}
$$

yields

$$
\begin{aligned}
\sum_{k} a_{j k}\left(\partial y_{k} / \partial \tilde{p}_{k}\right)\left(\partial \tilde{p}_{k} / \partial p_{i}\right) & =a_{j i}\left(1-a_{i i}\right)\left(\varepsilon_{i}^{s} y_{i} / \tilde{p}^{i}\right)+\sum_{k \neq i}-a_{j k} a_{i k}\left(\varepsilon_{k}^{s} y_{k} / \tilde{p}^{k}\right) \\
& =a_{j i}\left(\varepsilon_{i}^{s} y i / \tilde{p}^{i}\right)-\sum_{k=0}^{n} a_{j k} a_{i k}\left(\varepsilon_{k}^{s} y_{k} / \tilde{p}^{k}\right)
\end{aligned}
$$

Similar calculations give

$$
\begin{aligned}
\sum_{j} t_{j}\left(\partial y_{j} / \partial \tilde{p}_{j}\right)\left(\partial \tilde{p}_{j} / \partial p_{i}\right) & =\varepsilon_{i}^{s} t_{i} y_{i} / \tilde{p}^{i}-\sum_{j=0}^{n}-a_{i j}\left(\varepsilon_{j}^{s} y_{j} / \tilde{p}^{j}\right) \\
\sum_{j} t_{j}\left(\sum_{k} a_{j k}\left[\partial y_{k} / \partial w\right]\right) & =-\sum_{j} \sum_{k} t_{j} a_{j k}\left(\mu_{k} y_{k} / w\right)
\end{aligned}
$$


and

$$
\sum_{j} t_{j}\left(\partial y_{j} / \partial w\right)=-\sum_{j}\left(\mu_{j} t_{j} y_{j} / w\right)
$$

Finally, let $\tilde{\varepsilon}_{i}^{w}=\partial \log w / \partial \log \tilde{p}_{i}(>0)$ be the elasticity of the wage rate to a change in the net price of good $i$. The expression for the wage-rate adjustment term is given by:

$$
\begin{aligned}
\partial w / \partial p_{i} & =\sum_{k}\left(\partial w / \partial \tilde{p}_{k}\right)\left(\partial \tilde{p}_{k} / \partial p_{i}\right)=\sum_{k}\left(\partial w / \partial \tilde{p}_{k}\right)\left(1_{k=i}-a_{i k}\right) \\
& =\tilde{\epsilon}_{i}^{w} w / \tilde{p}_{i}-\sum_{k} a_{i k} \tilde{\varepsilon}_{k}^{w} w / \tilde{p}_{k}
\end{aligned}
$$

Combining these gives:

$$
\begin{aligned}
\varepsilon_{i} & =\sum_{j}\left(t_{j} c_{j} / p_{i}\right) \varepsilon_{i j}^{c}+\sum_{j} t_{j}\left(a_{j i}\left[\varepsilon_{i}^{s} y_{i} / \tilde{p}^{i}\right] \sum_{k=0}^{n} a_{j k} a_{i k}\left[\varepsilon_{k}^{s} y_{k} / \tilde{p}^{k}\right]\right) \\
& -\left(\left[\varepsilon_{i}^{s} t_{i} y_{i} / \tilde{p}^{i}\right]+\sum_{j=0}^{n} a_{i j}\left[\varepsilon_{j}^{s} y_{j} / \tilde{p}^{j}\right]\right) \\
& -\left[\left(\sum_{j}\left[\mu_{j} t_{j} y_{i} / w\right]\right)-\left(\sum_{j} \sum_{k} t_{j} a_{j k}\left[\mu_{k} y_{k} / w\right]\right)\right]\left(\tilde{\varepsilon}_{i}^{w} w / \tilde{p} i-\sum_{k} a_{i k} \tilde{\varepsilon}_{k}^{w} w / \tilde{p}_{k}\right) .
\end{aligned}
$$

If $P_{i}>0$, the existence of an interior solution with positive protection requires that $E_{i}<0$. As in the Grossman-Helpman model, the first term and the following two in parentheses are Ramsey terms minimizing the deadweight loss due to the tariff on good $i$. They are decreasing in the own-price elasticity of supply $\left(\varepsilon_{i}^{s}\right)$ and in (the absolute value of) the own-price elasticity of demand $\left(\left|\varepsilon_{i i}^{c}\right|\right)$; that is, $E_{i} \rightarrow-\infty$ (driving down the equilibrium tariff toward zero) when either $\varepsilon_{i i}^{c} \rightarrow-\infty$ or $\varepsilon_{i}^{s} \rightarrow \infty$. The expression in square brackets is a sum of secondbest terms reflecting the presence of positive tariffs on other goods; it is multiplied by a wage-adjustment factor in parentheses. Clearly, if there is no tariff other than $i\left(t_{j}=0\right.$ for all $\left.j \neq i\right)$ there is no second-best argument for a positive $t_{i}$ on efficiency grounds. But even with positive tariffs on other goods, the secondbest argument for a tariff in $i$ vanishes when all general equilibrium linkages picked up by cross-price elasticities of demand, input-output coefficients, and wage-rate adjustment are simultaneously zero, as in Grossman-Helpman.

Using the notation introduced in this appendix, equation 6 can also be rewritten in terms of elasticities and shares. Using equation $\mathrm{A} 4$, let $\tilde{\alpha}_{i}=w \ell_{i} / \tilde{p}_{i} y_{i}$ be the share of labor in sector $i$ 's value added, and let $\lambda_{i}=\ell_{i} / \ell$ be the share of sector $i$ in total employment, 


$$
\Phi_{i}=y_{i}-\sum_{j} a_{i j} y_{j}-\left(\left(\tilde{\alpha}_{i} / \lambda_{i}\right) \varepsilon_{i}^{w}-\sum_{k} a_{i k}\left(\tilde{\alpha}_{k} / \lambda_{k}\right) \tilde{\varepsilon}_{k}^{w}\right) y_{i} .
$$

\section{Appendix B. Equations and Calibration of the Simulation Model}

The first two equations in the simulation model are the government's first-order condition, given by equations A- 6 and A-5, which are indexed over tradables sectors (agriculture and manufacturing). Labor demand is indexed over all activities, and assuming that the nested value-added function is of the CES type, labor demand in sector $i$ ( $i=$ agriculture, manufacturing, or nontraded) is given by

$$
\ell_{i}=\left(\tilde{\alpha}_{i} \tilde{p}_{i} / w\right)^{\sigma i} y i .
$$

Finally, the following equation determines the equilibrium wage:

$$
\ell=\sum_{i} \ell_{i}
$$

Several elasticities in table B-2 are calculated internally from the data. This is the case for $\mu_{i}$, the wage elasticity of supply used in equation A-5, and $\eta_{i}$, the elasticity of labor demand used in the calibration of $\tilde{\varepsilon}_{i}^{w}\left(\tilde{\varepsilon}_{i}^{w}=\eta_{i} \ell_{i} / \sum_{j} \eta_{j} \ell_{j}\right)$, the elasticity of the wage rate to a change in the net price of $i$ used in equations A4 and A5.

\section{Data Sources}

Tables B-1 and B-2 give the data used in the simulations. Parameters describing technology and demand and production structures (like ratios of sectoral consumptions and productions) are taken from Anderson (1995, table 1). So are price elasticities of demand and the assumption of a Cobb-Douglas technology (except for sensitivity analysis). Anderson, however, does not provide information on input-output relationships. For the rich economy these were taken from de Melo and Tarr (1992). For the poor economy the coefficients are aggregated

TABLE B-1. Input-Output Coefficients for Rich and Poor Archetypes

\begin{tabular}{lllllllll}
\hline & \multicolumn{2}{c}{ Agriculture } & & \multicolumn{2}{c}{ Manufacturing } & & \multicolumn{2}{c}{ Nontradables } \\
\cline { 2 - 3 } & Rich & Poor & & Rich & Poor & & Rich & Poor \\
\hline Agriculture & 0.38 & 0.22 & & 0.04 & 0.09 & & 0.028 & 0.03 \\
Manufacturing & 0.26 & 0.04 & & 0.42 & 0.10 & & 0.26 & 0.05 \\
Nontradables & 0.07 & 0.05 & & 0.08 & 0.10 & & 0.11 & 0.05 \\
\hline
\end{tabular}

Source: See appendix B. 
Table B-2. Output Composition and Elasticities for Rich and Poor Archetypes

\begin{tabular}{|c|c|c|c|c|c|c|}
\hline & \multicolumn{2}{|c|}{ Agriculture } & \multicolumn{2}{|c|}{ Manufacturing } & \multicolumn{2}{|c|}{ Nontradables } \\
\hline & Rich & Poor & Rich & Poor & Rich & Poor \\
\hline$C$ & 7 & 35 & 12 & 10 & 31 & 20 \\
\hline$Y$ & 6 & 61 & 46 & 10 & 68 & 29 \\
\hline$\tilde{\alpha}_{i}^{\mathrm{a}}$ & 0.35 & 0.70 & 0.50 & 0.35 & 0.60 & 0.60 \\
\hline$\sigma_{i}$ & 1 & 1 & 1 & 1 & 1 & 1 \\
\hline$\mu_{i}^{\mathrm{b}}$ & 0.54 & 2.33 & 1 & 0.54 & 1.5 & 0.43 \\
\hline$\eta_{i}^{\mathrm{c}}$ & 1.54 & 3.33 & 2 & 1.54 & 2.5 & 1.43 \\
\hline$\lambda_{i}^{\mathrm{d}}$ & 0.031 & 0.761 & 0.379 & 0.065 & 0.590 & 0.175 \\
\hline$\tilde{\varepsilon}_{i}^{e}$ & 0.02 & 0.774 & 0.258 & 0.06 & 0.722 & 0.166 \\
\hline$\varepsilon^{i, i}$ & -0.12 & -0.25 & -0.52 & -0.69 & -0.21 & -0.49 \\
\hline
\end{tabular}

${ }^{\mathrm{a}} \tilde{\alpha}_{i}=w \ell_{i} / \tilde{p}_{i} y_{i}$.

${ }^{\mathrm{b}} \mu_{i}=\varepsilon_{i}^{s}\left(\sigma_{i} \tilde{\alpha}_{i}\right) /\left(1-\tilde{\alpha}_{i}\right)$.

${ }^{\mathrm{c}} \eta_{i}=\sigma_{i} /\left(1-\tilde{\alpha}_{i}\right)$.

${ }^{\mathrm{d}}$ For $w=1$.

${ }^{\mathrm{e}}$ For $w=1$ and from expression $\tilde{\varepsilon}_{i}^{w}=\left(\eta_{i} \ell_{i} / \sum_{j} \eta_{j} \ell_{j}\right)$.

Source: See appendix B.

from information used in Chenery and Syrquin (1986, chap. 4) for a typical economy with a $\$ 500$ GDP per capita (in 1970 dollars). The main difference in interindustry structure between the rich and poor economies in table B-1 is the higher value-added ratio in the poor economy due partly to the higher valueadded ratio in agriculture (see Chenery and Syrquin, figures 3.3 and 3.4). Table B-2 gives the remaining elasticities and shares.

\section{REFERENCES}

Ades, A., and R. Di Tella. 1999. "Rents, Competition and Corruption." American Economic Review 89(4):982-93.

Anderson, K. 1995. "Lobbying Incentives and the Pattern of Protection in Rich and Poor Countries." Economic Development and Cultural Change 43(2):401-23.

Cadot, O., J. de Melo, and M. Olarreaga. 2003. "The Protectionist Bias of Duty Drawbacks." Journal of International Economics 59(1):161-82.

Chenery, H., and M. Syrquin. 1986. “Typical Patterns of Transformation.” In H. Chenery, S. Robinson, and M. Syrquin, eds., Industrialization and Growth. New York: Oxford University Press.

Corden, W. M. 1974. Trade Policy and Economic Welfare. Oxford: Clarendon Press.

Destler, I. M., and J. S. Odell. 1987. “Anti-Protection: Changing Forces in US Trade.” Policy Analysis 21. Institute for International Economics, Washington, D.C.

Djankov, S., R. La Porta, F. Lopez-de-Silanes, and A. Shleifer. 2002. "The Regulation of Entry." Quarterly Journal of Economics 117(1):1-37.

Dornsbusch, R. 1974. “Tariffs and Nontraded Goods.” Journal of International Economics 4(2):177-85.

Findlay, R. 1991. “The New Political Economy: Its Explanatory Power for LDCs.” In G.M. Meier, ed., Political Economy and Policy Making in Developing Countries. San Francisco, Calif.: ICS Press. 
Freund, C., and S. Djankov. 2000. “The Politics of Trade Liberalization.” World Bank, Washington, D.C.

Gawande, K., and U. Bandyopadhyay. 2000. "Is Protection for Sale? Evidence on the Grossman-Helpman Theory of Endogenous Protection.” Review of Economics and Statistics 87(1):139-52.

Grossman, G., and E. Helpman. 1994. "Protection for Sale.” American Economic Review 84(4):833-50. 1996. "Electoral Competition and Special Interest Politics." Review of Economic Studies $63(2): 265-86$.

Hillman, A. L. 1982. "Declining Industries and Political-Support Protectionist Motives." American Economic Review 72(5):1180-87.

Koujianou-Goldberg, P., and G. Maggi. 1999. "Protection for Sale: An Empirical Investigation." American Economic Review 89(5):1135-55.

Krueger, A. O., M. Schiff, and A. Valdes. 1989. “Agricultural Incentives in Developing Countries: Measuring the Effect of Sectoral and Economy-wide Policies.” World Bank Economic Review 2(3):255-73.

Maggi, G., and A. Rodriguez-Clare. 1999. "Import Penetration and the Politics of Trade Protection." Journal of International Economics 51(2):287-304.

Mayer, W. 1984. "Endogenous Tariff Formation.” American Economic Review 74(5):970-85.

Melo, J. de, and D. Tarr. 1992. A General Equilibrium Analysis of U.S. Foreign Trade Policy. Cambridge, Mass.: MIT Press.

Moore, M. 1996. “Steel Protection in the 1980's: The Waning Influence of Big Steel?” In A. O. Krueger, ed., The Political Economy of American Trade Policy. Chicago: Chicago University Press.

Ray, E. J. 1990. "Empirical Research on the Political Economy of Trade.” In C. A. Carter, ed., Imperfect Competition and Political Economy. Boulder, Colo.: Westview Press.

- 1991. "Protection of Manufactures in the United States." In D. Greenaway, ed., Global Protectionism: Is the U.S. Playing on a Level Field? New York: St. Martin's Press.

Rodrik, D. 1995. "The Political Economy of Trade Policy." In G. Grossman and K. Rogoff, eds., Handbook of International Economics, vol. 3. New York: North Holland.

World Bank. 2000. World Development Indicators 2000. Washington, D.C.

WTo (World Trade Organization). Various issues. Trade Policy Reviews. Geneva. 